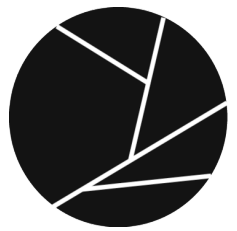

\title{
SOPHIA
}

PEER REVIEW JOURNAL

VISUAL SPACES OF CHANGE: DESIGNING INTERIORITY

SHELTER, SHAPE, PLACE, ATMOSPHERE

ISSN: 2183-8976 [PRINT] 2183-9468 [ONLINE]

Volume 5, Issue 1| Publication year: 2020

DOI 10.24840/2183-8976_2020-0005_0001_6

(c) SCOPIO EDITIONS

HOMEPAGE: HTTPS://WWW.SOPHIAJOURNAL.NET

\section{The Power Of Imagination}

\section{an interview to designer Hans Thyge, from Design, Interior \& Branding Studio Hans Thyge\& Co based in Norsminde, Denmark}

\section{by Fátima Pombo (FP) and Hans Thyge (HT)}

FP The motto of your Design Studio is that 'it all starts with the power of imagination. Every design should tell a story, on its own and as part of a bigger context'. What is the meaning for you of such statement?

HT Let me tell you a story that enlightens the meaning you are asking for. Many years back I was driving down to the Cologne furniture fair with two employees. We were driving late evening and started to discuss a new competition we were invited to take part of. It was about an ergonomic chair made of plywood for the contract market. In the night we discussed advantages and principles. After some talks back and forth, we suddenly discovered an interesting static principle, which could move the pivot point of the backrest up in the lumbar area. Immediately we felt that we had discovered something compelling while driving in the dark without pen and paper. The interesting thing was that we had elaborated an idea using 
our imagination and the spoken language even the matter was about three-dimensional form. The day after I flew to Poland after a long day at the fair, and I quickly sketched the principle down on the back of my ticket. The idea remained intact and worked after some experiments with prototypes. We often talk about "The power of imagination" which has become the motto of our small design studio. Design is about being able to imagine and sense stories and elements carried out in materials, with colours and surfaces. Theoretically there is no difference between writing a book, composing a piece of music or designing a chair. Whether it is the pencil or the very sophisticated 3D modelling programs we are using to elaborate our ideas, it always comes down to our ultimate ability to see and feel the object for our inner eye. Without that, designing becomes a superficial act dethatched from our personal life. A genius violinist once was asked where he got the ability to play so beautiful and he answered: "It is the sum of my life and all I see and experience everyday". Our power of imagination is a sum of the cultural input we are experiencing, or in other words all which our senses see and feel through our life. It is not only the capability of playing the notes or designing a chair...... the character and ingenuity of the expression is a matter of who we are, which will always be reflected in the things we create. (fig.1) 


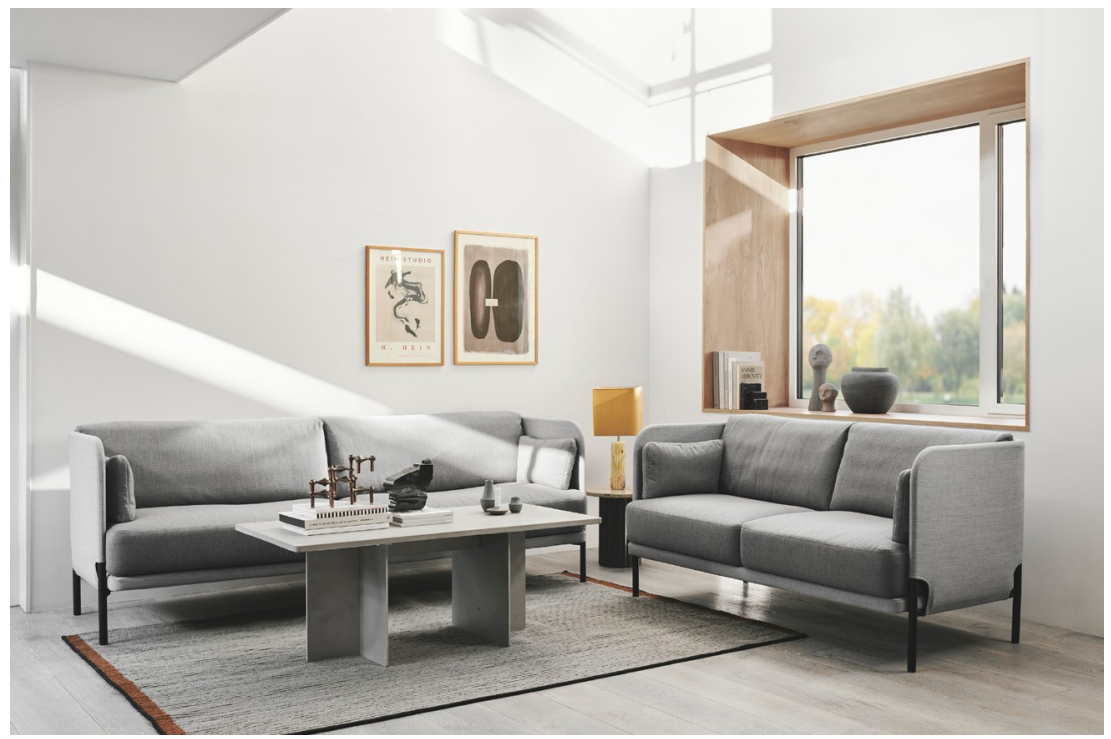

FP Hans Thyge \& Co design studio was founded in 1990 by you after living many years in Italy working with people behind the MEMPHIS group. Which is the heritage of MEMPHIS in your creative process, in the philosophy of your work?

HT MEMPHIS is the ultimate reaction towards the philosophy of BAUHAUS "form follows function". Suddenly MEMPHIS entered a completely new discussion about the cultural content of the object. Objects became posters, ironic statements, paintings with references to music, historic periods, fashion, rock'n roll and many other influences. We suddenly discovered that objects have a tremendous power in expressing our lives through our homes and surroundings like cloth on our body. BAUHAUS focused on the object as functional and a part of the essential life, where MEMPHIS opened up for the object as a container of emotion, humour, pop and loud music. As many movements did, MEMPHIS also ended up in its own trap trying to reinvent itself with artist making more and more obscure objects, but it does not cover the fact that the MEMPHIS in my eyes was the most influential movement within design

[Fig.1]

Design of Soho sofa for Labofa (2018), Denmark. 
and maybe also art in the last $\mathbf{4 0}$ years. To me, the two post-war movements Bauhaus and Memphis captures two fundamental elements in our approach to design in Hans Thyge\& Co. It seems strange that such two different movements have inspired equally, but the BAUHAUS created a focus on beauty in things. The proportions, the material.... the idea that you cannot hide anything in an object and the fact that design should be reworked and reworked until the inner beauty is revealed.

Bringing that quality into the area of Pop art and MEMPHIS it feels that the circle is complete, with the focus on the meaning and the storytelling of the objects. We are storytellers. Our studio is specialized in designing furniture, objects, interiors and branding. Branding has become a more important part of our design than before, as bringing the stories of the products out in a wider perspective is more relevant than ever. There are so many products in the world today, the ability to communicate is imperative. So, we are storytellers as well as designers.

FP Considering that design is so involved with narratives, what is your departure point to sketch a product, in which 'ground' do you dig a design proposal or a design solution?

HT Design is about the interesting mix between shape, function, size, materials and about culture, values, context, stories, the future and much more. Design is very complex, and still it can be very simple. Sometimes the simplest things are the hardest things to design. Either way design requires analytic and practical skills combined with intuition, sensibility and aesthetics. At Hans Thyge \& Co we practice a holistic approach, where we try to always see the product in a larger context. By taking all of these things into consideration in a design, we have the possibility to interpret the visions and DNA of our clients and to create interesting appealing stories to the users.

If you work with design and space, you should have a profound interest in these matters. Creating nice objects has a strong link to seeing objects in space and rooms, whether the space is your hand, or it is about a big sofa interacting with the architecture. We have always worked for many international clients and over the last six years intensively in Asia. Working with international customers requires that our cultural compass is always adjusted and many times our design get an interesting twist from the cultures we are working with. When you meet other cultures it requires an openness, understanding the differences and habits which will always influence the design you make, and it challenges the idea that the culture you are living in often will be considered better and more interesting than others. (fig.2)

FP In your Studio you work with 'interiors'. Do you face it as a challenge to create spatial experiences and staging atmospheres? 


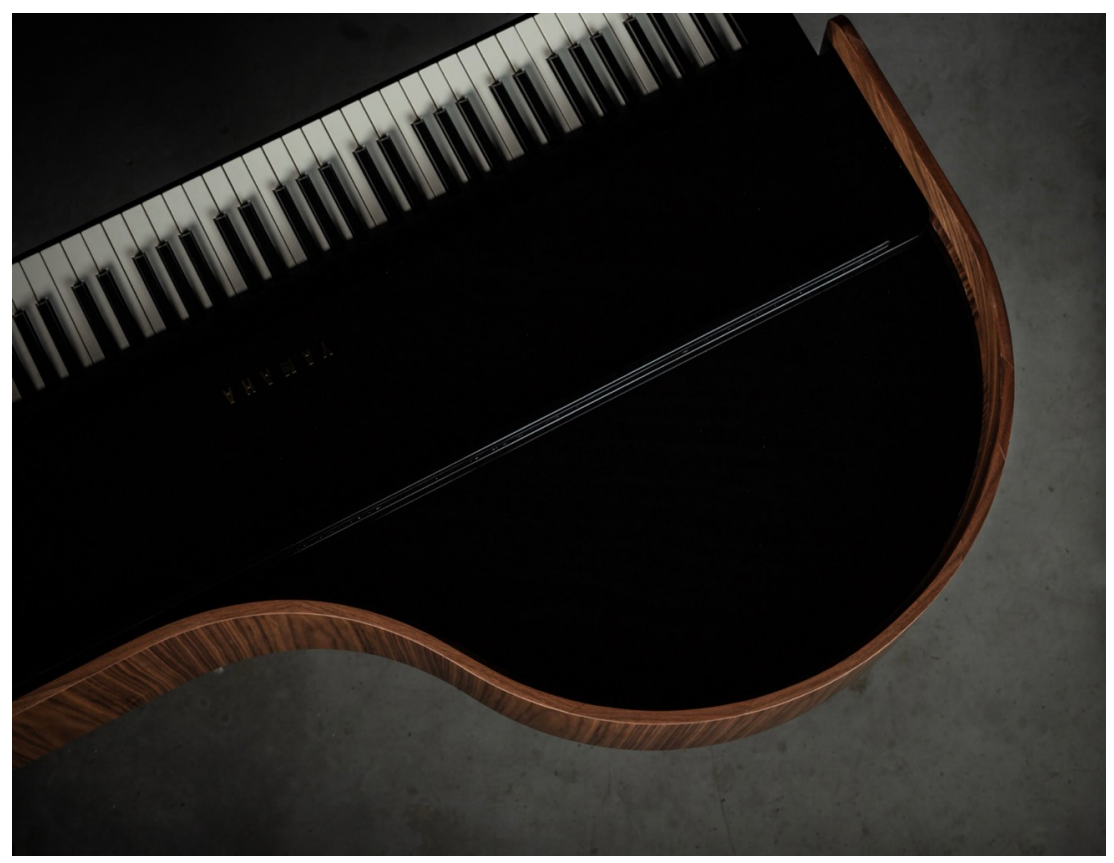

HT We take into consideration movement, functions, sound, smell, tactility, surfaces, colours, furniture, objects and lightning. The interaction between these elements are very important as they create the atmosphere of the room.

Interior design can be seen as the frame of where the sculptural furniture and objects will be viewed. Both elements have a great impact on each other and can never be fully understood as individual parts.

FP You have been designing furniture for years, namely a lot of chairs. What does mean for you designing furniture? And why is that interesting to design so many chairs?

[Fig.2]

Design of sculptural piano for Yamaha \& Mexarts (2018), Japan/China. 
HT Designing furniture, we work with a sculptural approach. Furniture and objects have to relate to the human body and has to be understood and admired from all angles. At the same time, they should be diverse as they have to fit in to different environments. Over the years we have designed almost 100 chairs and you ask why is that interesting? It is not interesting in itself, as there are enough chairs in the world, but as a sculpture and a piece of scientific investigation the chair has it all. It is the mirror of the human body. It has all the static engineering problems, it carries on the history of every century of our life, it is seen in the room, it is just everywhere as the ultimate sculpture imposing soul into white walls and space. It is a task that we MUST work with to all times to find the expression that captures the essence of the time we are living in. The chair evokes all the senses we have. It makes small noises sitting, we feel it on our body, it keeps track of time and the nice chair is the ultimate song for the eye. No matter the size you work with, may it be architecture, interior, furniture or smaller objects the outcome is a result of thoughts and feelings based on senses. $n$ our practice we have experienced that the 5 common senses are not enough. We work with the 6 th sense as proprioception - how your brain understands where your body is in space and the 7th sense we see as our emotion or intuition. Where the intuition is based on experiences and visions merged together. Design is a constant process where you must criticize your expression and refine things until there is not a gram fat too much on things. Sometimes, which is rare, you think an object is close to perfection, I have sometime questioned myself how it actually was made......there has been a sense that the object was always there out of time and context. (fig. 3)

FP You speak about the process of designing as a continuum of self-reflexion and consequent self-criticism in which 7 senses play a role. Do you have the feeling that living/inhabiting in your own design allows you to be creator and creature and therefore to unfold the possibility of a dialogue between both characters of the story that design may tell?

HT The way we live, and our own home becomes in many ways our lab, where thoughts are generated and where we see our prototypes, use things, test functions. The object in itself very often takes other character, when it comes to life and get settled in physical space. Maybe a chair is more dominant and less inviting to sit in as expected. Many designs take colour after the surroundings and that is the whole idea by living permanently or temporarily with your own things. Design is fundamentally about seeing things and by having the things around you see things in different moods, lights, circumstances and that's is where the learning process starts.15 years ago, I designed and built my own house, which was one of the crucial things in my career as a designer as it ultimately made me think about my own behaviour, the way I lived and my values in life. The house is a wooden and minimalistic archetype form sitting on the beach with a wild grassland between the beach and the house. It has a monolithic form with big cut outs for windows. It opens up facing the landscape in front of the house and closes towards the passing road on the backside of the house. Only wood is exposed on the outside together with the big glass windows. The cedar wood with its silver-grey 
tone and saw cut rough surface is perfectly blending in with the nature all year around from the cold part of the year with the brown grey coloured grass to the summer where the sea with its blue tones and the big wild green grass field with lots of wild flowers. The grey cedar wood also shows the aging of the house which is influenced by the strong winds and rugged weather at the coast so next to the aesthetics, materials, form etc. it also have the sense of time represented in the building.

We have kept the garden also at a very minimalistic stage, where the wild nature runs practically all the way up to the house. Inside the house it is kept in a very tight minimalistic white look as a contrast to the outside wilderness. The theme inside is the detailing, materials meeting each other and refined build in light systems. The house inside represents maybe the idea of the gallery or a place of background of all the things we create. Sometimes we even go outside to see how things are perceived through the windows. I know it might seem like we are presenting our lives as a set-design, but that is not the case. We are creating a constant changing painting, where we look at our designs in order to understand the depth and the message laid down in the things. My wife and I are still building and refining the house inside as we constantly see things we want to change or optimize. The process and discussion become a part of our work and considerations. (fig. 4)

FP I guess that you apply in your Studio the same attitude of discussing and exchanging ideas with your collaborators, am I right?

HT We always have students and interns in our studio, as we believe that inputs and the process of teaching and listening together with young people must always be the basis of good design. Mantras as: " we have already tried that" or why should we do this?" must never be the driver in a creative process. The interns in the studio always get the responsibility of some new products and then we help each other to find the way. Despite products are always under way for a year or two, we believe in short processes...prepare and find all elements in the task, describe the elements in the job with care and then you are ready. In our studio we bring ideas to the table fast and insist on trying them out as we believe that discussion having proposals to look at make us all more and more clear about what way to go. Fast sketching listening and then constant dialogue along the project, where many other designers will give their input along the process. The design should always withstand the discussion and dialogue within the studio and never become a private story without common appeal. A design can have personality from the designer but must always get out of the personal "I like it myself" sphere. It is also a very important part to train people and next generations of designers, as I strongly believe that design is a skill like many other skills. The idea that a mason train new generations of masons how to lay the bricks, about the patterns, and all techniques is the idea that society has a common knowledge, that we are handing over and also a tribute to the idea that a skill is not only something we can describe on Wikipedia or google, but a much more complex matter formed by people interacting with people. 


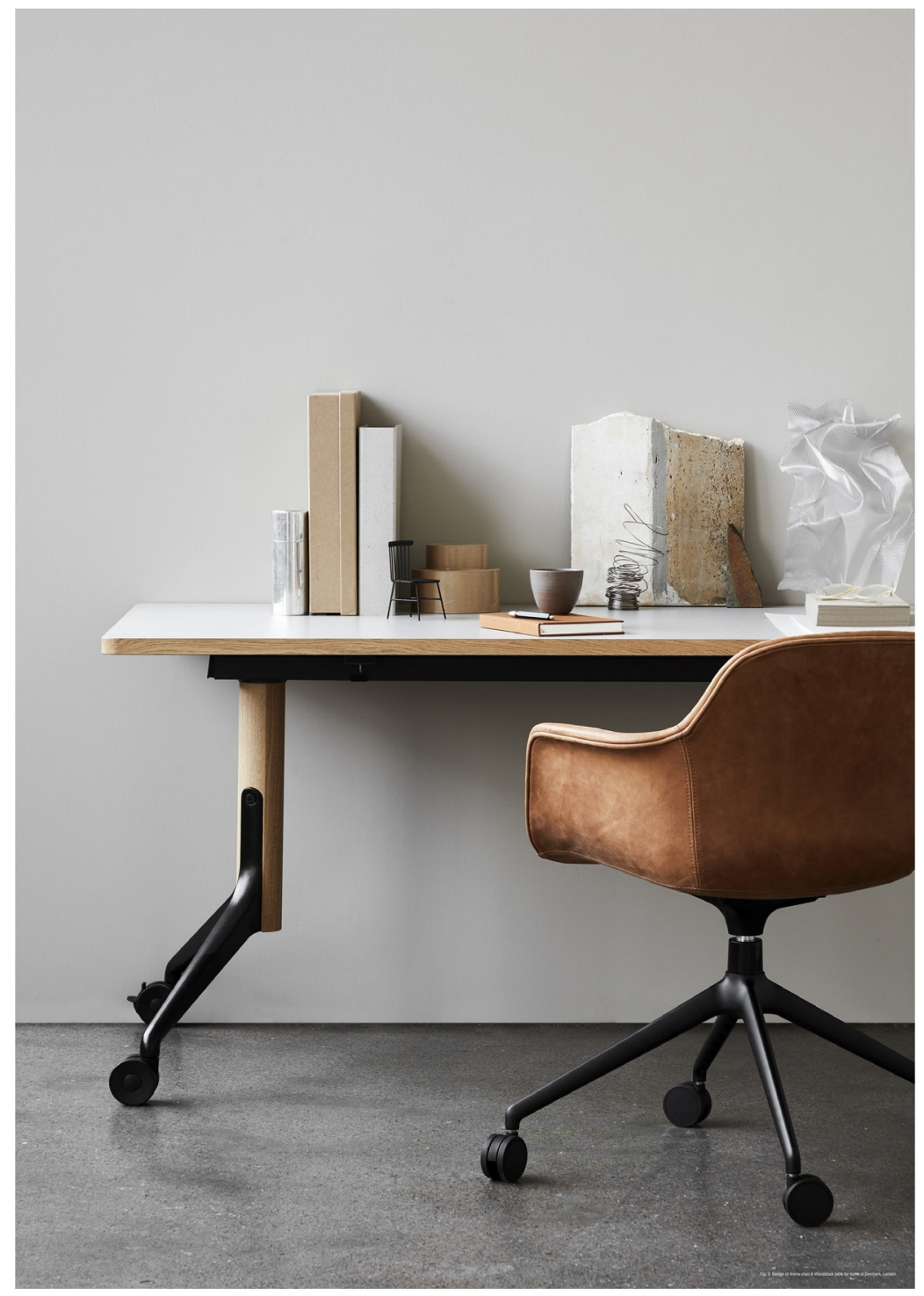

[Fig.3]

Design of Arena chair (2018) \& Woodstock table (2017) for Icons of Denmark, London 


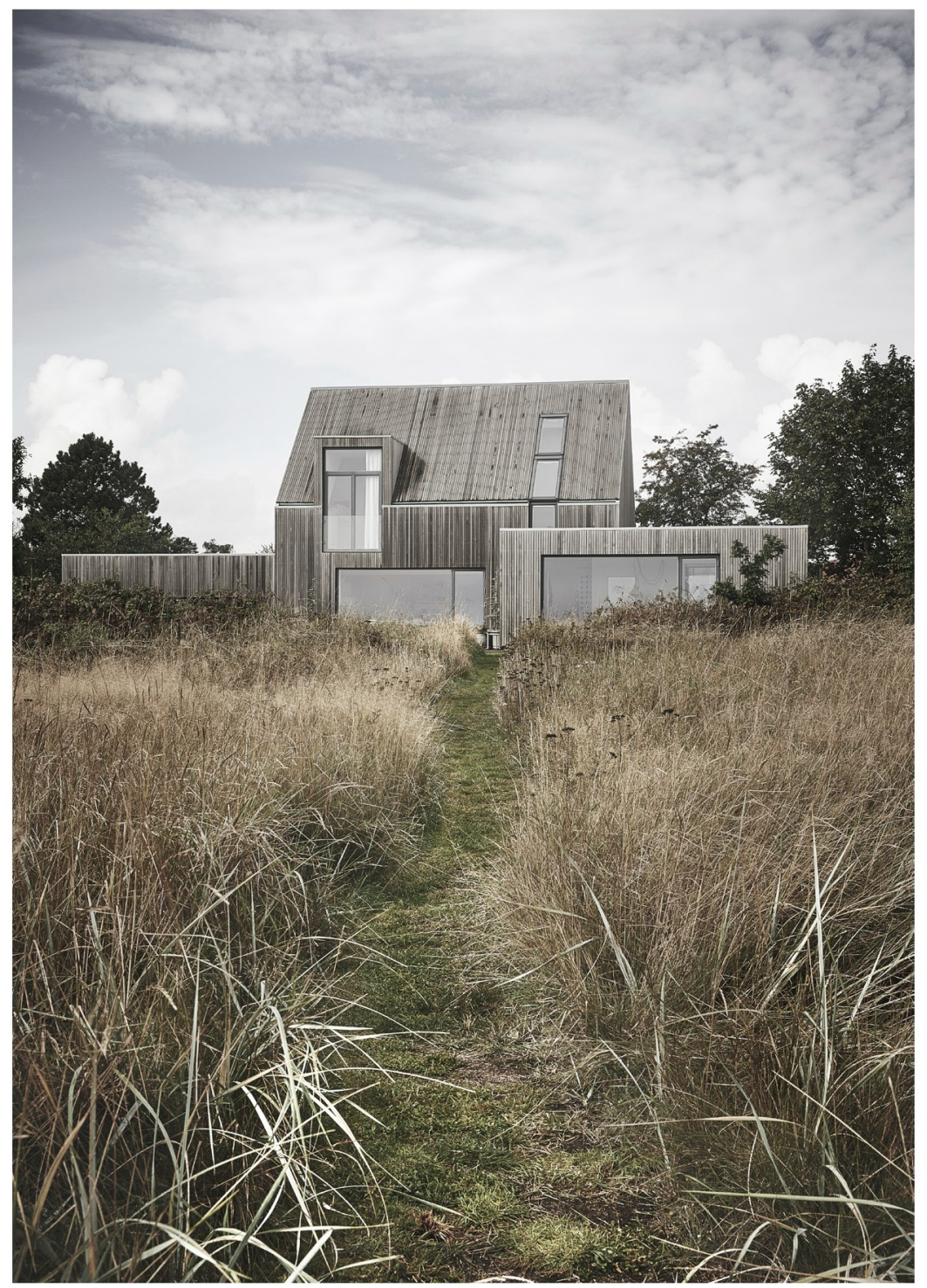

[Fig.4]

Hans TllygeRaunkjaers private house \& design studio (2007), Denmark 
FP So, you stimulate in the Studio the dialogue within a certain pedagogical atmosphere, is it?

HT One of our best designers in the studio was actually studying technical design and he came in the studio as intern. Besides the technical drawing he had great flair and passion for design. Somehow, he was not the type who was destined to go to design school, so after he finished school becoming technical draftsman, we offered him an apprenticeship over 3 years training him to become a designer. The idea that we trained him working with all kind of tasks from research, writing, sketching and designing, layout, graphic work etc. was a very satisfactory way of seeing a person taking over the knowhow and experience of the studio. We think this way of education is missing in the design field.

FP Let me ask you now your opinion about one of the core topics that surround us from all directions we turn our attention to, I mean sustainability. How do you see the relation between sustainability and design?

HT The environment is in everybody's thoughts these days - sustainability is the key word. However, sustainability is a very complex thing, as it can be understood in many different ways and levels. As designers we think that our first priority must be to make objects that have a quality that evoke emotions. Objects must create awareness and impact. Good design is like a piece of good music......it touches our memories and feelings and we get a relation to the object as the humans in old days had a relation to their tools or arms. By doing that, we can maybe plant a small seed making people look at objects and things around us in another way. Fighting empty consumerism is making people like objects for their emotional content and quality as opposed to the feeling of joy buying things. To create objects that has a long lasting life is in our opinion the most important element of design and can this work be combined with materials that get beauty over time and use or which can be disposed safely or is made from recycled resources then the circle is complete. There must be an interest in aesthetics and beauty. We live in a time, where everything in the design-world is about user integrated design, saving the world and much more of the same and I agree about the necessity of social responsibility creating objects into a world full of super flu things and lack of global resources. However, we must have the sense of beauty and the passion for design in us to be able to communicate ideas and political stories. A music piece is driven by musicians that play and who have the tones and music in their blood and so it must be with designers. We must see spaces and enjoy playing with materials and rooms and to fill them with our objects to learn and refine our ideas. Our canvas is our home, our creativity, our moral compass and the way we live and love. Good design comes with compassion and interest in our surroundings on all levels from placing a nice colour on a piece of wood, to creating things that solve urgent global problems. Nothing is too big and nothing too small.

FP And you practice the 'sound' of good design in the sense you just explained us with traditional instruments: pencil and paper. Why? 
HT After 30 years in design I still only use my pencil and paper, and which is sometimes laughed about, but despite all the fantastic tools we have around to create nice design, I strongly believe that mind craft compared with a small tactile piece of pencil can make it. The ultra-split second between my thought and the scratch on the paper is where most poetry is born. Over the years I have many times talked in Universities about the importance of the sketch and reading the sketch, as that is where the power is buried.

FP To finish this so inspiring and triggering talk with you, which I very much thank, what would you still like to add to this story?

HT As designers our social behaviour, our interacting with other people creating products, the progress bringing design forward during yearlong processes must be done with care and respect. Not only in respect of the client, but also in respect of society, nature, the environment and the objects itself. We are responsible for making both courageous, but also reasonable and aesthetic choices. We need to be able to understand and reflect on the society and generally the time we live in and give an indication of what demand will come and which trends we believe will influence the future. We use brain, heart, soul and mind .It all starts with the power of imagination! (fig.5)

[Fig. 5]

Hans Thyge \& Co (2019).

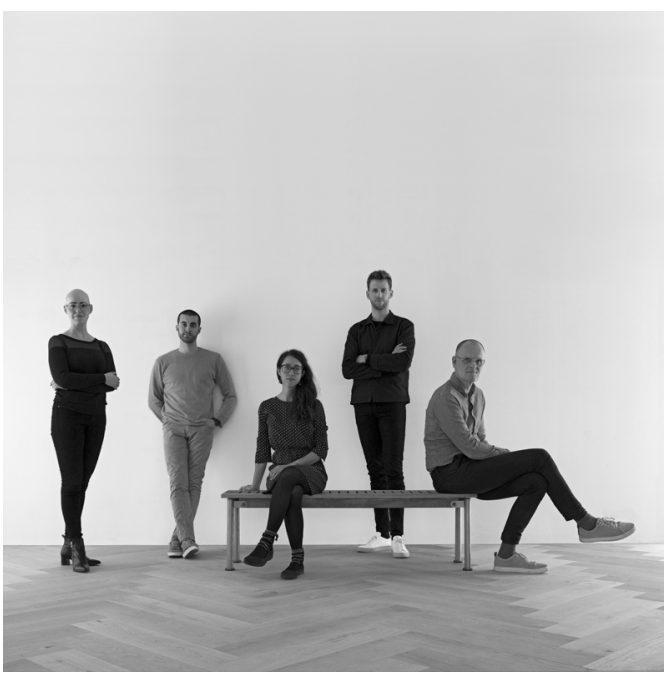

